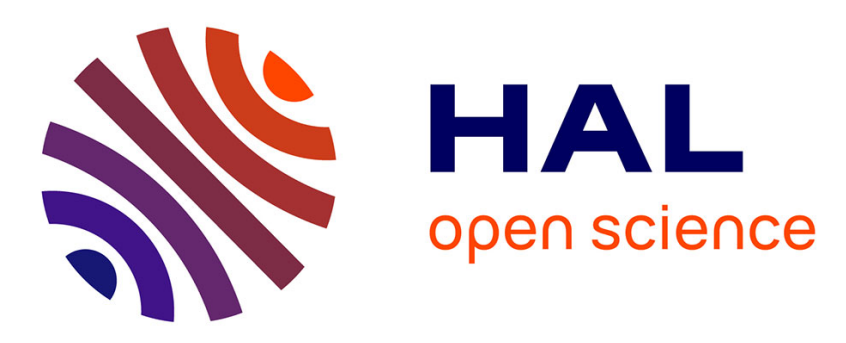

\title{
A real time electromyostimulator linked with EMG analysis device
}

Maxime Yochum, Toufik Bakir, Romuald Lepers, Stéphane Binczak

\section{To cite this version:}

Maxime Yochum, Toufik Bakir, Romuald Lepers, Stéphane Binczak. A real time electromyostimulator linked with EMG analysis device. Innovation and Research in BioMedical engineering, 2013, 34, pp.4347. 10.1016/j.irbm.2012.12.003 . hal-00826684

\section{HAL Id: hal-00826684 https://hal.science/hal-00826684}

Submitted on 28 May 2013

HAL is a multi-disciplinary open access archive for the deposit and dissemination of scientific research documents, whether they are published or not. The documents may come from teaching and research institutions in France or abroad, or from public or private research centers.
L'archive ouverte pluridisciplinaire HAL, est destinée au dépôt et à la diffusion de documents scientifiques de niveau recherche, publiés ou non, émanant des établissements d'enseignement et de recherche français ou étrangers, des laboratoires publics ou privés. 


\title{
A real time electromyostimulator linked with EMG analysis device
}

\author{
Maxime Yochum, Toufik Bakir, Romuald Lepers and Stéphane Binczak
}

\begin{abstract}
In this study, a new system composed of two modules (electromyostimulation + electromyography recording) is presented. It can analyze in real time EMG signals during electromyostimulation. In addition, we propose a new method based on wavelet decomposition to analyze changes in M-wave characteristics. It leads to introduce a new index related to muscular fatigue.
\end{abstract}

\section{INTRODUCTION}

The characterization of muscles behavior over electrical evoked contractions is useful in several domains as for medical muscles diagnosis [1] [2], in particular for paralyzed patients who cannot have muscular feeling [3]. They are also used in rehabilitation devices for instance to observe changes after a rehabilitation session [4]. An easy way to obtain muscular information is the electromyogram (EMG) [5] which is an integration of potential action spreading into muscular fibers under electrodes. We call this signal $\mathrm{V}_{\mathrm{EMG}}$. During electrical stimulation, $\mathrm{V}_{\mathrm{EMG}}$ signal takes a particular shape named $\mathrm{M}$ wave. This shape varies over the stimulation and can lead to estimate muscular fatigue. The literature contains already some fatigue indexes as the peak to peak (PTP), the root mean square (RMS), the mean $\left(\mathrm{F}_{\text {mean }}\right)$ and the median frequency $\left(\mathrm{F}_{\text {med }}\right)$ ones [6][8] which are used to estimate the muscular fatigue during electrical stimulation. This study introduce a system which can perform an electrically evoked stimulation and record EMG signals at the same time. This coupling lead to analyze the fatigue state of a muscle under electrical stimulation with fatigue indexes used in literature and a new one based on wavelet transform by using continuous wavelet transform (CWT) called $\mathrm{I}_{\mathrm{CWT}}$ [9]. It gives an estimation of the dilation of the $\mathrm{M}$ wave over a stimulation that is an indicator of fatigue [10], [11]. The eletrostimulator and EMG recording device are linked to a Labview software which performs fatigue algorithm and stimulation pulses management. An example of the fatigue indexes is given for four consecutive stimulations.

\section{MATERIAL}

\section{A. Overview of Material}

We introduce a new electro stimulator dedicated to the electrical stimulation of a muscle and to fatigue analysis based on EMGs feedback in real time, as shown in Fig. 1 which presents the general diagram of the system. The

M. Yochum, S. Binczak and T. Bakir are with the Laboratoire LE2I UMR CNRS 6306, Université de Bourgogne, 9 avenue Alain Savary, 21078 Dijon, France. (e-mail: stbinc@u-bourgogne.fr)

R. Lepers is with the laboratory INSERM U887, Université de bourgogne, 21078 Dijon cedex, France. (e-mail: romuald.lepers@u-bourgogne.fr) device is composed of a dedicated hardware part conceived to deliver current impulse stimulations and EMGs acquisition. A software part enables the control of the stimulation and computes the fatigue index. A NIDaq module [12] connects these two parts in order to obtain a system processing in real-time, the myostimulation and EMG being performed at the same time.

\section{B. Hardware}

1) Stimulation board: The figure 2 represents the layout board. As each muscle has its own characteristics such as impedance, therefore, in order to obtain an accurate stimulation, the same current must be injected in a generic way whatever specific is the stimulated muscle. This task is performed by the circuit proposed by Han-Chang $\mathrm{Wu}$ $\&$ al [13]. The board works symmetrically, the top and bottom parts is respectively for positive and negative pulse phases. The software generates stimulation voltage pulses from $-10 \mathrm{~V}$ to $10 \mathrm{~V}$ which are converted into current pulses from $-100 \mathrm{~mA}$ to $100 \mathrm{~mA}$. The OPAs copy the voltage $V_{i n}$ onto $V_{\text {opa }}$ with a null input current. Then, pulse voltages are converted in current pulses thanks to $R 1$ and $Q 1$ in order to obtain $I c$ such as

$$
I c=\frac{V_{o p a}}{R_{1}}=\frac{V_{\text {in }}}{R_{1}} .
$$

This current can be maintained thanks to the high tension on $V D D$ and $-V D D$ in order to have a controlled and precise current for a large range of muscle impedance. $I c$ is then copied into the stimulation electrodes $I_{\text {load }}$ by a Wilson current mirror $\left(Q_{2}, Q_{3}, Q_{4}, R_{2}\right.$ and $\left.R_{3}\right)$.

2) $E M G$ board: Surface electrodes are used to acquire the electrical activity of the stimulated muscle. It is a non invasive equipment but their positions must be accurate as EMG signals vary according to their location on the skin [14]. As shown in Fig. 3, three EMG electrodes are required : two for the recording of the electrical activity (named $E_{1}$ and $\left.E_{2}\right)$ and another one laid on a bony point $\left(E_{r e f}\right)$ acting as a reference. This board performs the difference between

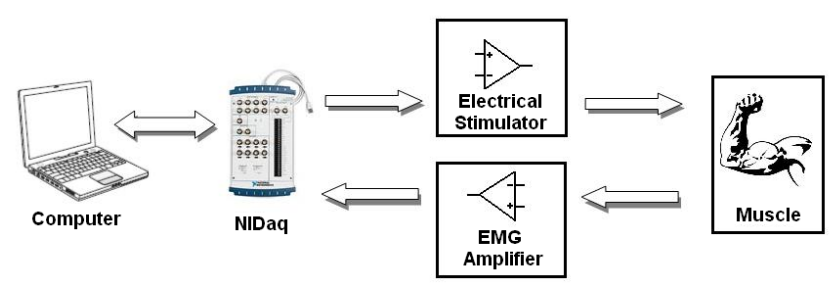

Fig. 1. General diagram of the device 
two voltages of the muscle with a large amplification and reference erasing. The EMG board layout can be divided into three stages : The first one consists of a suppression of the reference voltage, yielding to give us the monopolar voltage of each electrode. This deletion is performed separately for $E_{1}$ and $E_{2}$ with two instrumentation amplifiers (INA128 from Texas Instruments) $U_{1}$ and $U_{2}$ which have a high CMMR $(120 \mathrm{~dB})$ allowing a good suppression of common voltage. Additionally, a preamplification is possible by tuning variable resistors $R P_{1}$ and $R P_{2}$. At the output of the first stage, there are two monopolar muscular voltages without reference disturbance, expressed such as

$$
V_{E i}=\left(E_{i}-E_{r e f}\right) \cdot G_{i}, \text { with } G_{i}=\frac{50}{R P_{i}},
$$

where $i=\{1,2\}$ indicates which electrode is concerned and $R P_{i}$ is in $K \Omega$. In many EMG amplifiers, just one INA is used to obtain the difference between the two muscular electrodes [15]. Here, the muscular activity of each electrode can be investigated. Then, to obtain the bipolar voltage between both electrodes $E_{1}$ and $E_{2}$, the difference between them is performed. The same method (eq. 2) is used, consequently $V_{E M G}=G_{3} \cdot\left(V_{E 1}-V_{E 2}\right)$. An offset and amplification adjustment is also available by tuning $\mathrm{POT}_{3}$ and $\mathrm{RP}_{3}$ if necessary. Note that $V_{E M G}$ can be filtered with a pass band filter after this stage.

Pictures of those two boards are shown in Fig. 4.

3) Bound between software and boards: A connection is necessary between the hardware parts and the computer which manages the stimulation pulses and analyzes the EMG signal. The NIDaq 6251 from National Instrument has been chosen to do this link [24]. This module can provide a digital to analog conversion at 2.8 Mega sample per second with 16 bits of precision and an analog to digital conversion at 1.25

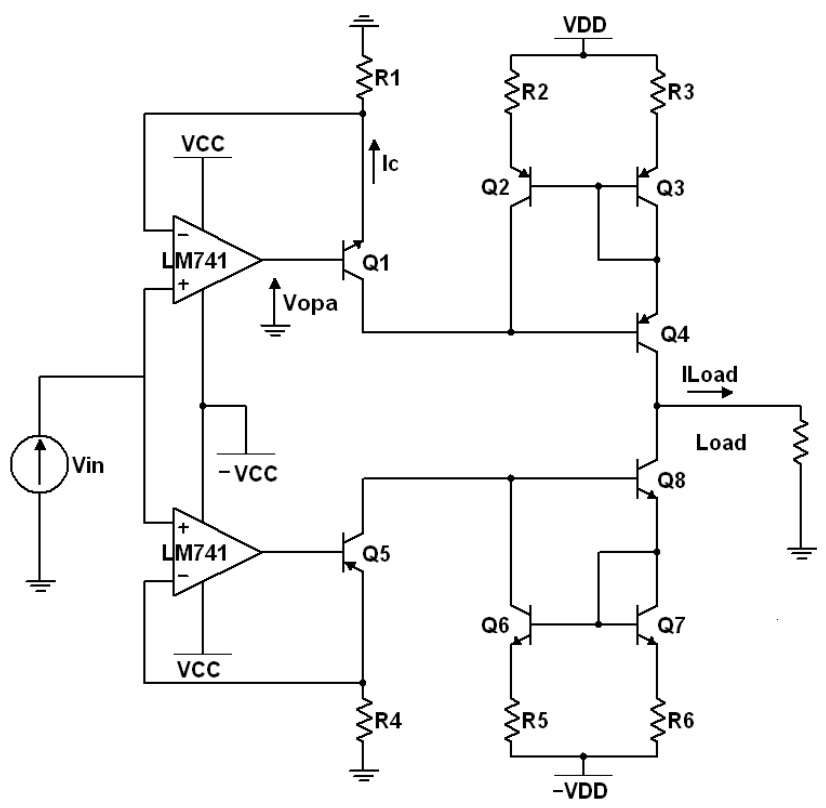

Fig. 2. Stimulation diagram
Mega sample per second also on 16 bits which is largely enough for our sampling ratio of ten thousand samples per second.

\section{Software}

Many stimulation parameters can be adjusted though HMI (human machine interface). That allows to have a lot of different stimulation shapes available. The current amplitude can vary from $0 m A$ to $\pm 100 m A$. As the stimulation board can supply a constant current, this one is not dependent of stimulated muscles. The duration of pulses varies from $500 \mu s$ to $2000 \mu s$. The range of frequency of pulse train starts at $10 \mathrm{~Hz}$ and ends at $100 \mathrm{~Hz}$. The shapes of pulses used for myostimulation can be chosen between the most common ones, such as Monophasic, Biphasic, Dual Biphasic, Asymmetric Biphasic and Doublet Nlet [16], [17] ones, but it can also be arbitrary. The stimulation and rest duration can also be adjusted, whereas EMGs and results of fatigue treatments can be saved during the stimulation process. The kind of fatigue treatment is also adjustable. Values of the different parameters of the stimulation can be set during the myostimulation, and they can be taken into account on the next pulse train. Some graphical windows are included to the HMI yielding the possibility to observe in real time the evolution of the stimulation and EMG signal parameters over time. The layered $M$ wave is depicted to view the changes of the shape of $\mathrm{M}$ wave in time in comparison with reference $\mathrm{M}$ wave. The results of fatigue analysis selected by the user can also be represented. The treatments performed on EMG signals are written in Matlab language. When a user chooses a specific fatigue treatment from HMI window, Labview Software call those functions. In addition to this fatigue index proposed in this study, which is based on continuous wavelet transform (CWT), the most common fatigue indexes have been implemented and are presented in section II-D [6]-[8], [18]-[20] are also implemented.

\section{Fatigue Indexes extraction}

Fatigue estimation is computed for each $M$ waves of a stimulation train. The fatigue index based on CWT $\left(\mathrm{I}_{\mathrm{CWT}}\right)$

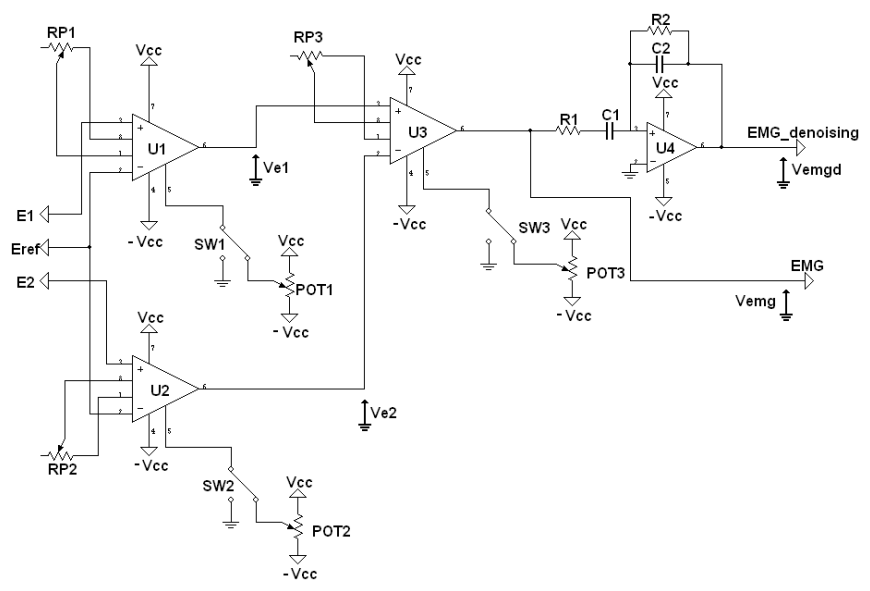

Fig. 3. EMG lay-out diagram. 


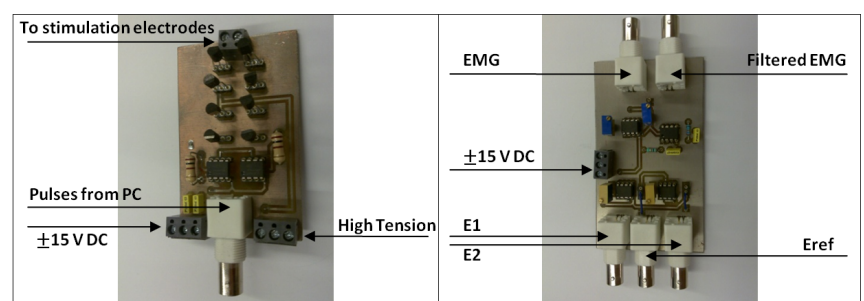

Fig. 4. Photography of PCB. left : Stimulation board; right : EMG board.

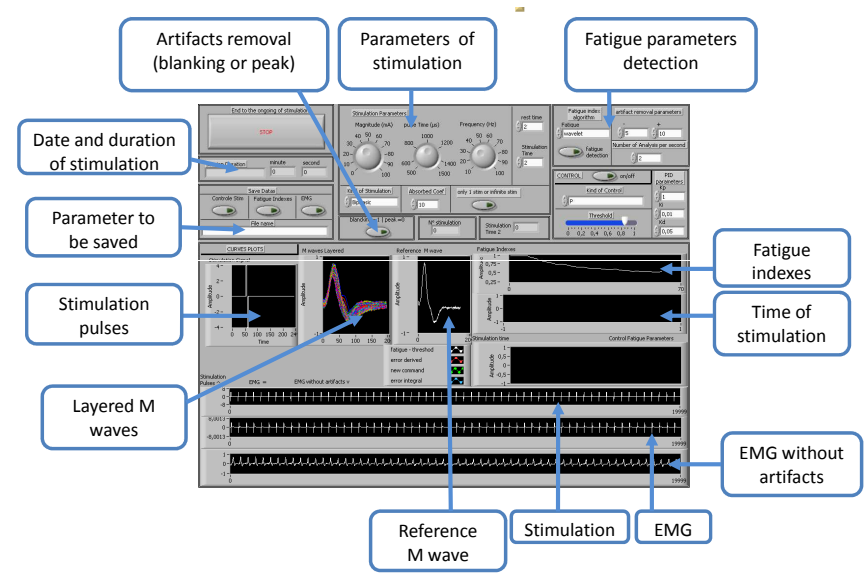

Fig. 5. Software interface with some management blocs to define stimulation and fatigue treatment parameters and some display blocs to visualize stimulation, EMG and fatigue signals.

has been detailed in [9]. Briefly, It gives an estimation of the temporal dilation undergone by $\mathrm{M}$ waves during an electrical stimulation thanks to the CWT equation

$$
C_{a, b}\left(V_{E M G}, \hat{\psi}(t)\right)=\int_{\infty}^{\infty} V_{E M G} \frac{1}{\sqrt{a}} \hat{\psi}\left(\frac{t-b}{a}\right),
$$

where $\hat{\psi}$ is an estimated wavelet obtained from the first $\mathrm{M}$ wave of the stimulation using mean square optimization method, $a$ is a scale factor and $b$ indicates the temporal location. Then, a local maxima research is done on the CWT coefficient results. That leads to find the $a$ scale parameters giving the maximum values of $C_{a, b}\left(V_{E M G}, \hat{\psi}(t)\right)$. Therefore, the $a$ scale parameter represents the temporal dilation of $\mathrm{M}$ wave. The found $a$ values are then inverted because the other fatigue indexes from literature tend to decrease over time while $a$ values increase. So, to keep the same tendency, the fatigue index $\mathrm{I}_{\mathrm{CWT}}$ is given as

$$
I_{C W T}=\left[\underset{a}{\operatorname{argmax}}\left\{C_{a, b}(s(t), \hat{\psi}(t))\right\}\right]^{-1} .
$$

Four other fatigue indexes from literature [6]-[8], [18]-[20] have also been implemented. Some of them are related to the amplitude of $M$ waves. Is the case for the Peak to Peak value (PTP) which is computed as

$$
P T P=V_{E M G_{\max }}-V_{E M G_{\min }},
$$

and also the RMS parameter, computed from the total surface area of $\mathrm{M}$ waves amplitudes, such as

$$
R M S=\sqrt{\frac{1}{n} \sum_{i=0}^{n} V_{E M G} i^{2}} .
$$

The two last fatigue indexes are obtained in the frequency domain. The first one is the mean frequency which is an average of the total power spectrum, computed such as

$$
F_{\text {mean }}=\frac{\sum_{i=0}^{n} P S D_{i} \cdot f_{i}}{\sum_{i=0}^{n} P S D_{i}},
$$

where $P S D$ is the power spectrum density of $\mathrm{V}_{\mathrm{EMG}}$ and $f$ is the frequency scale parameter. The second one is the median frequency, which is the frequency sharing the total spectrum density in two equal parts :

$$
\sum_{i=0}^{F_{\text {med }}} P S D_{i}=\sum_{i=F_{\text {med }}}^{n} P S D_{i}=\frac{1}{2} \cdot T S D,
$$

where $T S D$ is the total spectrum density.

All previous fatigue indexes are normalized to vary between 0 and 1 . The fatigue indexes are normalized as :

$$
n F_{\text {index }}=\frac{F_{\text {index }}}{\max \left(F_{\text {index }}\right)},
$$

where $F_{\text {index }}$ is the fatigue index among $\mathrm{I}_{\mathrm{CWT}}$, PTP, RMS, $\mathrm{F}_{\text {mean }}$ and $\mathrm{F}_{\text {med }}$. In Fig. 6, an illustration of these fatigue index results are given, which correspond to the electrical evoked contraction on the right biceps with stimulation parameter as follows : $50 \mathrm{~Hz}, 50 \mathrm{~mA}, 1 \mathrm{~ms}$ pulse duration, a biphasic shape and $10 \mathrm{~s}$ long. They all decrease in different ways as the fatigue is increasing during the stimulation. Those changes are linked to physiological changes of muscular fibers [19]-[21].

\section{E. Experimental results}

For our experiments, the pulses parameters have been set in order to deliver a biphasic symmetric stimulation
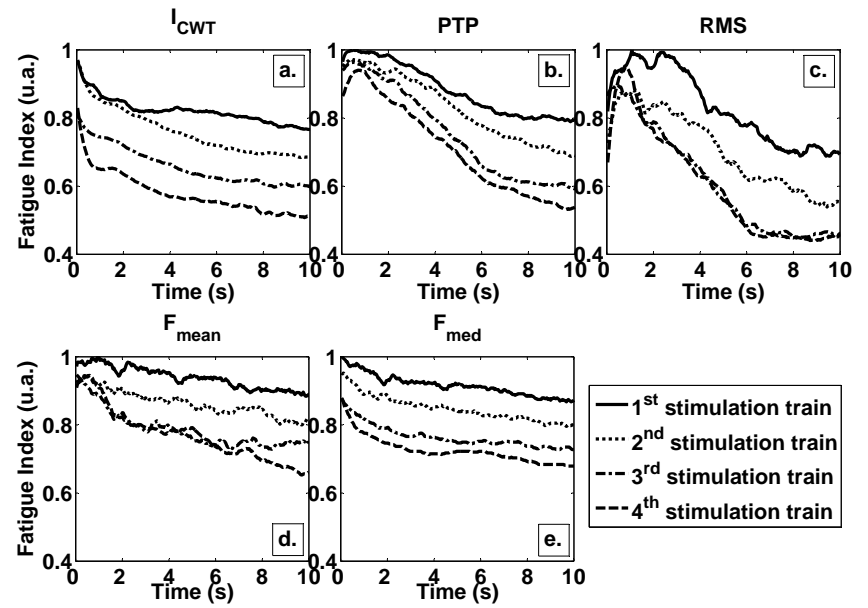

Fig. 6. Example of fatigue indexes for 4 consecutive contractions at $10 s$ of stimulation and $10 s$ of rest time : a. $\mathrm{I}_{\mathrm{CWT}}, \mathrm{b}$. PTP, c. RMS, d. $\mathrm{F}_{\text {mean }}$, e. $F_{\text {med }}$. 
with a 30,40,50,60 and $70 m A$ intensity, a $1 \mathrm{~ms}$ pulse duration, a 20,30,40,50 and $60 \mathrm{~Hz}$ pulse train frequency. All stimulations have been applied on the biceps brachia isometrically, the position of arm and forearm were fixed. It is interesting to observe the differences of fatigue indexes during several consecutive contraction exercises. In the Fig. 6 , fatigue indexes have been plotted for 4 consecutive $10 \mathrm{~s}$ stimulations with a rest time between each stimulations of $10 \mathrm{~s}$. For all five fatigue indexes, the fatigue becomes more and more important over the stimulation trains. The fatigue index based on CWT follows the same tendency. This decrease to low values could be explained by the fact that the muscle does not have the time to recover its initial condition during the $10 s$ of rest, therefore the muscle becomes increasingly tired.

\section{CONCLUSION}

Through this article, a presentation of an electrical stimulator device with an electromyogram feedback is performed thanks to a software design with Labview and Matlab algorithm. This feedback allows to compute fatigue indexes based on continuous wavelet transform named $\mathrm{I}_{\mathrm{CWT}}$ in a real time way. The changes of shape of $M$ waves are analyzed to find which are the dilatation of the $M$ waves between the beginning of the stimulation and throughout the stimulation. In addition, the software can use some other fatigue indexes from literature among the most classic ones based on $\mathrm{M}$ waves amplitude (peak to peak and root mean square) or frequencies (mean and median frequencies).

\section{REFERENCES}

[1] A. Labarre-Vila, "Électromyographie de surface et fonction musculaire en pathologie," Revue Neurologique, vol. 162, no. 4, pp. 459-465, 2006.

[2] M. Zwarts, G. Drost, and D. Stegeman, "Recent progress in the diagnostic use of surface EMG for neurological diseases," Journal of Electromyography and Kinesiology, vol. 10, no. 5, pp. 287-291, 2000.

[3] J. Mizrahi, M. Levy, H. Ring, E. Isakov, and A. Liberson, "EMG as an indicator of fatigue in isometrically FES-activated paralyzed muscles," Rehabilitation Engineering, IEEE Transactions on, vol. 2, no. 2, pp. 57-65, 1994.

[4] J. Moseley, F. Jobe, M. Pink, J. Perry, and J. Tibone, "Emg analysis of the scapular muscles during a shoulder rehabilitation program," The American Journal of Sports Medicine, vol. 20, no. 2, pp. 128-134, 1992.

[5] P. Konrad, "The abc of emg," A Practical Introduction to Kinesiological Electromyography, vol. 1, 2005.

[6] J. Mizrahi, O. Levin, A. Aviram, E. Isakov, and Z. Susak, "Muscle fatigue in interrupted stimulation : effect of partial recovery on force and EMG dynamics," Journal of Electromyography and Kinesiology, vol. 7, no. 1, pp. 51-65, 1997.

[7] D. Tepavac and L. Schwirtlich, "Detection and prediction of FESinduced fatigue," Journal of Electromyography and Kinesiology, vol. 7, no. 1, pp. 39-50, 1997.

[8] N. Chesler and W. Durfee, "Surface EMG as a fatigue indicator during FES-induced isometric muscle contractions," Journal of Electromyography and Kinesiology, vol. 7, no. 1, pp. 27-37, 1997.

[9] M. Yochum, T. Bakir, R. Lepers, and S. Binczak, "Estimation of muscular fatigue under electromyostimulation using cwt," IEEE transaction on Biomedical Engineering, 2012.

[10] R. Merletti and L. Lo Conte, "Advances in processing of surface myoelectric signals : Part 1," Medical and Biological Engineering and Computing, vol. 33, no. 3, pp. 362-372, 1995.
[11] L. Lo Conte and R. Merletti, "Advances in processing of surface myoelectric signals : Part 2," Medical and Biological Engineering and Computing, vol. 33, no. 3, pp. 373-384, 1995.

[12] N. Instruments, "Ni usb-6251 bnc." 16-Bit, 1.25 MS/s M Series, Integrated BNC, External Power.

[13] H. Wu, S. Young, and T. Kuo, "A versatile multichannel directsynthesized electrical stimulator for FES applications," IEEE Transactions on Instrumentation and Measurement, vol. 51, no. 1, pp. 2-9, 2002.

[14] S. Rutkove, R. Partida, G. Esper, R. Aaron, and C. Shiffman, "Electrode position and size in electrical impedance myography," journal of the International Federation of Clinical Neurophysiology, vol. 116, no. 2, p. 290, 2005.

[15] L. Mesin, R. Merletti, and A. Rainoldi, "Surface EMG : The issue of electrode location," Journal of Electromyography and Kinesiology, vol. 19, no. 5, pp. 719-726, 2009.

[16] T. WATANABE, N. MIURA, N. HOSHIMIYA, and Y. HANDA, "The possibility of using $\mathrm{m}$-waves related to double pulses for evaluating muscle fatigue in fes control.," Japanese Journal of Medical Electronics and Biological Engineering, vol. 38, no. 1, pp. 42-48, 2000.

[17] Z. Karu, W. Durfee, and A. Barzilai, "Reducing muscle fatigue in FES applications by stimulating with N-let pulse trains," IEEE Transactions on Biomedical Engineering, vol. 42, no. 8, pp. 809-817, 2002.

[18] C. Thomas, "Fatigue in human thenar muscles paralysed by spinal cord injury," Journal of Electromyography and Kinesiology, vol. 7, no. 1, pp. 15-26, 1997.

[19] J. Mizrahi, "Fatigue in muscles activated by functional electrical stimulation," Crit. Rev. Phys. Rehabil. Med, vol. 9, no. 2, pp. 93-129, 1997.

[20] N. Dimitrova, J. Hogrel, T. Arabadzhiev, and G. Dimitrov, "Estimate of M-wave changes in human biceps brachii during continuous stimulation," Journal of Electromyography and Kinesiology, vol. 15, no. 4, pp. 341-348, 2005.

[21] R. Merletti, M. Knaflitz, C. De Luca, et al., "Electrically evoked myoelectric signals," Crit Rev Biomed Eng, vol. 19, no. 4, pp. 293340, 1992. 